\title{
Research on Optimizing the Planning Process of Project Scheduling on Substation Equipment
}

\author{
Ying LIU \\ Nanjing SAC Automation Co., Ltd \\ Nanjing, China \\ E-mail: ying-liu@sac-china.com
}

Lei ZHAO

Nanjing SAC Automation Co., Ltd

Nanjing, China

E-mail: lei-zhao@sac-china.com

\section{Long-Sheng CHENG*}

School of Economics and Management

Nanjing University of Science and Technology

Nanjing, China

* Corresponding Author

E-mail: cheng_longsheng@163.com

\author{
Jin-Yan CHEN \\ Nanjing SAC Automation Co., Ltd \\ Nanjing, China \\ E-mail: gina-jinyan.chen@sac-china.com
}

\author{
Xue-Jun QIAO \\ Nanjing SAC Automation Co., Ltd \\ Nanjing, China \\ E-mail: xuejun-qiao@sac-china.com
}

\begin{abstract}
In order to optimize the development process of substation equipment project schedule. Six Sigma methodology was used to analyze the progress plan of substation equipment engineering project, to find out the key factors which influenced on the precision of project planning, delivery rate on time and inventory index as the improvement focal point. After the improvement of the key factors such as the real delivery time, the standard task execution cycle, the project planning process, the project planning tools and the project plan delivery mode, two important indexes such as delivery rate on time and inventory management level were improved, and the work efficiency and user satisfaction were all improved further. The research also showed that six sigma is a kind of scientific management method, which is suitable for the optimization of the project schedule.
\end{abstract} Sigma

Keywords- Engineering Project; Process Optimization; Six

\section{INTRODUCTION}

With the development of science and technology, there have been many large and complex projects, which have many processes and a wide range of cooperation. They are often deployed with a lot of people, money and resources. In this condition, how to organize them rationally and effectively, with limited resources and the lowest cost in the shortest time to complete the project goal has become a prominent problem.

The project schedule is to make the progress of the project in accordance with the scheduled time to complete the time plan, project activities and project allocation of resources, through the specific project and the implementation of specific measures to develop the project to ensure the smooth progress of the project. Through the analysis of the overall situation of the project, the implementation of the sub-objectives to implement the implementation plan, so that all aspects of the project can be a reasonable arrangement and control to ensure the smooth completion of the project. In the implementation of the project, unreasonable progress plan may result in waste of resources, quality decline, and customer dissatisfaction and so on.

The purpose of scheduling is to strive for the optimal use of available manufacturing resources for producing good quality products with minimal cost and timely delivery [1]. In today's highly competitive business environment, project management's ability to schedule activities and monitor progress within strict cost, time, and performance guidelines is becoming increasingly important to obtain competitive priorities such as on-time delivery and customization [2]. Project schedule planning method can effectively improve the project management performance, including the key path method and plan review technology-based project network plan planning method [3].

Since its introduction by Motorola in the 1980s, six sigma and its philosophy have found widespread application in many manufacturing industries [5]. The term "Six Sigma" has developed as an aspirational quality measure for organizational processes (a "good" organization usually being "four Sigma" or higher). Therefore, the main theme of Six Sigma is that of focusing on reducing variability in processes [6]. Six sigma utilizes the concept of statistical 
thinking and encourages the application of well-proven statistical tools and techniques for defect reduction through process variability reduction methods (e.g. statistical process control and design of experiments) [7]. Six Sigma has evolved into a set of well-established system approach to problem solving, and the Six Sigma specific model that drives the continuous improvement of the enterprise is the DMAIC, which represents the five stages of the Six Sigma improvement, D (defined phase), M (measurement phase ), A (analysis phase), I (improvement phase), C (control phase)[7].

In this paper, the Six Sigma methodology is used to analyze the progress plan of the substation equipment project, to find the key factors influenced the accuracy of the project plan, the delivery rate and the inventory index, and take the corresponding measures to improve and compare with the improvement to verify the improvement effect.

\section{CASE STUdy}

Nanjing SAC Automation Co., Ltd. has three main businesses: controlling equipment on power transmission, construction of equipment engineering project, equipment installation and debugging. In order to carry out a comprehensive process optimization, the project management department was set up, then, the project management mode of project manager is the core of the replacement by the functional departments of pipeline operation management mode, which strengthens the ability to control the project and the project group management and macro control ability. Project management department to bear the main indicators are: project delivery rate, inventory, income resources. Also, the progress plan link play a major role in the impact on the above three indicators, therefore, the company decided to choose Six Sigma as the improvement tool of substation equipment project schedule development process optimization to ensure the realization of core indicators.

In order to deal with the problem highlighted and to achieve the research objectives, the Six Sigma (DMAIC) improvement methodology has been adopted to embark on the research. The phases of DMAIC and the tools used within each phase are discussed below.

\section{A. Define Phase}

The aim of this phase is to determine the customer and process requirements and define the scope and goals of the improvement project accordingly. The main customer of this project is the user and the managements of the company, the users want to deliver the goods in time, while the managements hope to reduce the operating capital. Therefore, the key of process optimization are the improvement on time delivery rate and the reduction of inventory. The improvement team decided to consider the Order to Delivery (OTD) and inventory amount as the Critical to Quality (CTQ) characteristic for this project.
Since this project is a process optimization project, it was necessary to perform a SIPOC (Supplier-Input-ProcessOutput-Customer) analysis to have a better understanding of the process, SIPOC analysis as shown in Table 1.

\section{B. Measure Phase}

According to the monthly discrete OTD data, the Measurement System Analysis (MSA) method and the P control chart are used in this phase to diagnose the measurement system and the stability of the process. The specific MSA methods are shown as follows:

Step 1: Randomly selected 20 ERP order lines corresponding to the items delivered during March 2014 to August 2014;

Step 2: Three people were arranged to compared with the data automatically calculated by the ERP system and the real data, in order to verify the accuracy of the result input and calculated by the measurement system;

Step 3: In accordance with the selected sample, each project manager measured twice independently.

The results showed that all the coincidence percentages between inspectors and standards are all greater than $80 \%$, thus the measurement system is acceptable.

According to the OTD data from March 2014 to August 2014, the data for each month is divided into four weeks and the first week of September 2014 is supplemented. A total of 25 OTD data and the $P$ chart are obtained, and it showed that the project delivery schedule is stable.

\section{Analysis Phase}

Cause and effect analysis was conducted to identify the possible causes for untimely and inaccurate data as shown in figure. 1 .

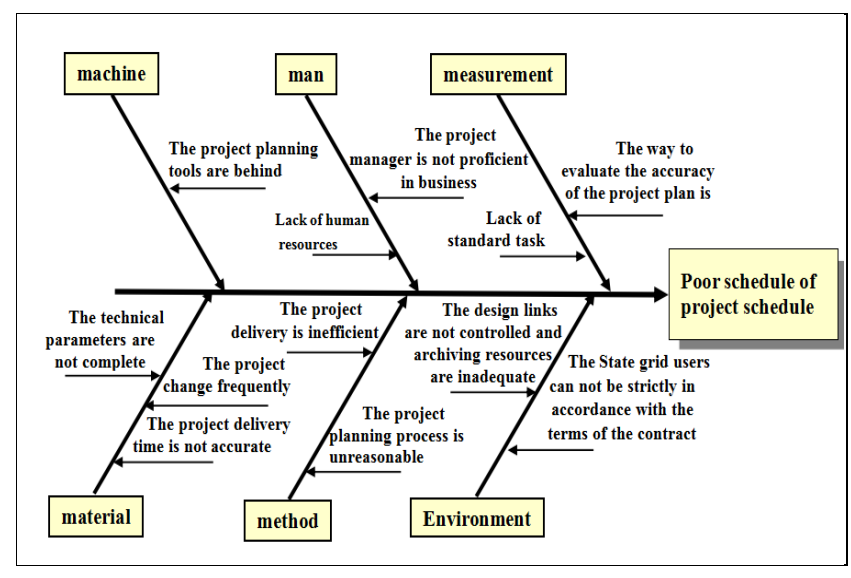

Figure 1. Cause and effect diagram

According to the substation equipment engineering project schedule, 15 factors which affect the accuracy of the project are selected and the results are shown in Table 2. 
TABLE I. SIPOC ANALYSIS

\begin{tabular}{|c|l|l|l|c|}
\hline Supplier & \multicolumn{1}{|c|}{ Input } & \multicolumn{1}{c|}{ Process } & \multicolumn{1}{c|}{ Output } & \multicolumn{1}{c|}{ Customer } \\
\hline Marketing & Contracts & The project progress plan formulation, include three steps: & Step 1: Marketing department issues the project task book; \\
Manager & \& Orders & $\begin{array}{l}\text { Step 2: The business units compile the department monthly output plan; } \\
\text { Step 3: Planning department to prepare monthly purchasing plan }\end{array}$ & $\begin{array}{l}\text { Overall } \\
\text { schedule }\end{array}$ & $\begin{array}{c}\text { Each function } \\
\text { link }\end{array}$ \\
\hline
\end{tabular}

TABLE II. THE IMPACT FACTOR SCORE

\begin{tabular}{|l|c|c|c|c|}
\hline \multicolumn{1}{|c|}{ Customer rating (1 10) } & 9 & 7 & & \\
\hline \multicolumn{1}{|c|}{ Impact factor } & OTD & $\begin{array}{l}\text { Inven } \\
\text {-tory }\end{array}$ & Score & $\begin{array}{c}\text { Influenc } \\
\text { e weight }\end{array}$ \\
\hline $\begin{array}{l}\text { Actual delivery time of the } \\
\text { project }\end{array}$ & 10 & 8 & 146 & $15.72 \%$ \\
\hline Contract & 2 & 1 & 25 & $2.69 \%$ \\
\hline Technical Parameters & 2 & 1 & 25 & $2.69 \%$ \\
\hline Net profit rate & 1 & 2 & 23 & $2.48 \%$ \\
\hline Monthly management indicators & 3 & 3 & 48 & $5.17 \%$ \\
\hline Monthly production capacity & 2 & 1 & 25 & $2.69 \%$ \\
\hline Design archiving resources & 8 & 6 & 114 & $12.27 \%$ \\
\hline Standard task execution cycle & 8 & 8 & 128 & $13.78 \%$ \\
\hline Project planning tools & 5 & 5 & 80 & $8.61 \%$ \\
\hline Project planning process & 4 & 6 & 78 & $8.40 \%$ \\
\hline $\begin{array}{l}\text { Accurate method of judging } \\
\text { project plan }\end{array}$ & 2 & 1 & 25 & $2.69 \%$ \\
\hline $\begin{array}{l}\text { Project manager's level of } \\
\text { business }\end{array}$ & 3 & 3 & 48 & $5.17 \%$ \\
\hline $\begin{array}{l}\text { The human Resources of Project } \\
\text { Manager }\end{array}$ & 2 & 2 & 32 & $3.75 \%$ \\
\hline Project plan delivery mode & 7 & 6 & 105 & $11.30 \%$ \\
\hline The State network users & 2 & 1 & 25 & $2.69 \%$ \\
\hline
\end{tabular}

It was shown in table 2 that there are eight factors score more than $40 \%$, namely: actual delivery time of the project, monthly management indicators, design archiving resources, standard task execution cycle, project planning tools, project planning process, project manager's level of business, project plan delivery mode.

The Failure Mode and Effect Analysis (FMEA) was carried out for the eight main factors selected above. Then, 50 extension or serious inventory samples of the project were randomly selected to conduct FMEA. Using the method of surveying statistical tables, the relevant project managers are required to identify and quantify the factors that influence the sample project. As a result of FMEA, the following five factors are selected: actual delivery time of the project, standard task execution cycle, project planning process, project planning tools, project plan delivery mode.

\section{Improve Phase}

In this phase Six Sigma project aims to eliminate the identified defects through the knowledge derived from analyze phase. As it mentioned modification of critical factors which cause deviation from target CTQs and goal, result in elimination of defects, enhancement of sigma level and performance improvement.

\section{E. 1solutions for Optimizing the Planning Process of Project Scheduling}

Five key factors are established in the analyzing phase, next we will research on the current situation, then proposed corresponding solutions and achieving goals for every key factor.

1) Accuracy Of Project's Delivery Date

The main problem for delivery date is that the accuracy of meeting original delivery date which is appointed in the contract is less than $20 \%$, even nobody is responsible for this specially. For this phenomenon, this paper proposed that some workers are assigned to confirm three times in one project at important points, which are point of receiving the project, point of finishing the planning process, point of completing the project.

2) Accuracy Of Standard Project's Execution Cycle

Facing the uncertainty of execution cycle, we divide the project into seven parts through Work Breakdown Structure (WBS), including design, manufacture, purchase, and dispatch in one set, debug, and joint debug and put in storage. We obtain the standard execution cycle of the whole project by clarifying this of every part. Table 3 shows the establishing process of standard project's execution cycle based on the example of integrated automation project.

TABLE III. OPTIMIZATION OF INTEGRATED AUTOMATION PROJECT'S EXECUTION CYCLE

\begin{tabular}{|c|c|c|c|c|c|c|}
\hline Type & \multirow{4}{*}{$\begin{array}{c}\text { Integrated } \\
\text { automation } \\
\text { project }\end{array}$} & Secondary division & design & $\begin{array}{c}\text { Manufacture } \\
\text { /purchase/ } \\
\text { dispatch in one set }\end{array}$ & $\begin{array}{c}\text { Debug/ } \\
\text { Joint debug/ } \\
\text { put in storage }\end{array}$ & Cycle \\
\hline A1 & & $\begin{array}{l}\text { Above } 220 \mathrm{kV} \text { requires } \\
\text { joint debug }\end{array}$ & 44 & 16 & 4+30(joint debug) & 94 \\
\hline A2 & & $\begin{array}{l}\text { Below } 110 \mathrm{kV} \text { requires } \\
\text { joint debug }\end{array}$ & 44 & 16 & 4+15(joint debug) & 79 \\
\hline $\mathrm{A} 3$ & & $\begin{array}{l}\text { Below } 110 \mathrm{kV} \text { not } \\
\text { requires joint debug }\end{array}$ & 44 & 16 & 4 & 64 \\
\hline
\end{tabular}

At present, the whole company only has a monthly production plan without task plans corresponding to every critical point, which leads to the low efficiency of work and 
delaying of order's delivery. For this phenomenon, it is suggested that detailed project scheduling should be made by project manager and schedules can be adjusted based on results of confirming the delivery date at the critical point.

\section{4) Tools For Planning the Project Scheduling}

Due to shortage of special tools for planning the project scheduling in this company, integrated information platform

Plan transferring and information synchronization are still inconvenient to achieve in the province. This paper proposed that the company can present the project scheduling, get feedback on problem and fill in the electric forms on completion, which makes information public and traceable. At the same time, integrated information platform named HERE can also be applied into data analyzing through the whole project in the controlling phase and detecting the time deviation between planning completion and actual completion to obtain the relative accuracy of project scheduling.

\section{F. The Optimization Effect of Project Scheduling}

\section{1) Effect of Improving Otd}

For the two different business units of the company PC1 and PC21, before the improving plans carrying out, the average OTD of $\mathrm{PC} 1$ and $\mathrm{PC} 21$ are $76.7 \%$ and $75.8 \%$ respectively, from March to August in 2014. After improving plans being carried out, the average OTD of PC1 and PC21 has been improved to $90.7 \%$ and $92.6 \%$, from October in 2014 to March in 2015. Figure.2 shows the effect of improving OTD.

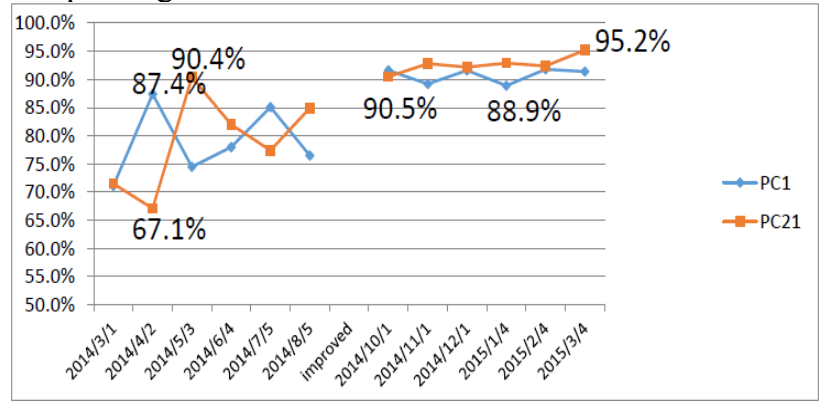

Figure 2. Curve figure of OTD

\section{2) Effect of Improving Inventory}

After improving plans being carried out, the average inventory of PC1 dropped to 20769 from 26215 and that of PC21 dropped to 5417 from 6376 from September in 2014 to March 2015, which reveals that inventory are effectively controlled. Figure. 3 and Figure. 4 shows curves of PC1 and PC21's inventory. named HERE is applied into managing and planning the project, including planning make, planning transfer and planning control.

5) Transfer Mode of Project Scheduling

At present, paper form, Excel, QQ, Email and LAN(Local area network) are common ways to share the project scheduling inside the company, meanwhile, plan gathering,

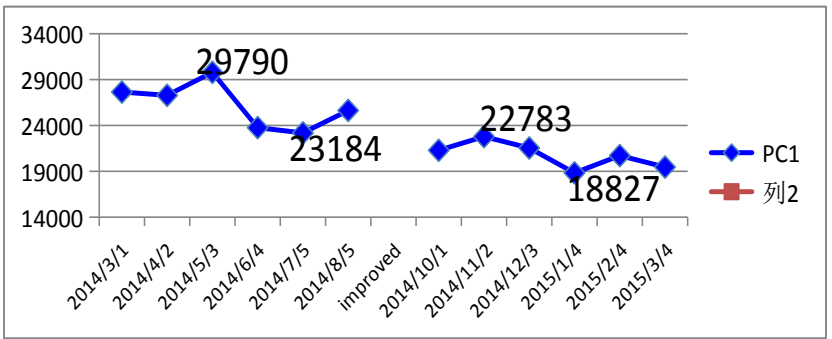

Figure 3. Curve figure of PC1's inventory (unit: ten thousand yuan)

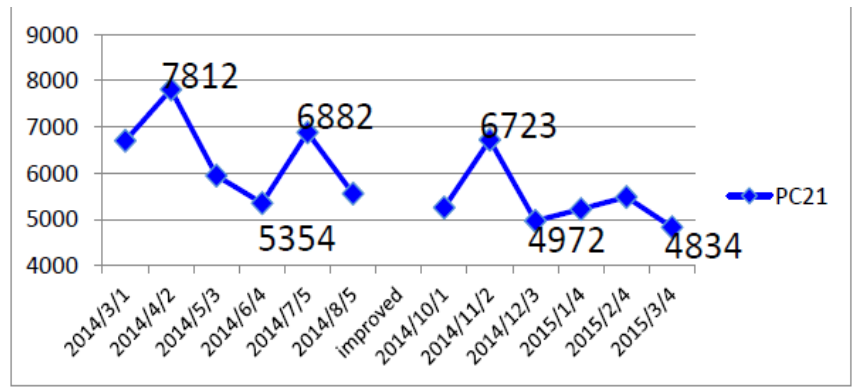

Figure 4. Curve figure of PC21's inventory (unit: ten thousand yuan)

\section{3) Effect Of Project Benefit's Estimate}

Based on the average reduction value of inventory, the actual benefits are 3.84 million Yuan per year conservatively; based on the average level of this industry, the actual benefits can be up to 8.97 million Yuan per year for one project.

Based on the improving level of OTD, in average, the execution cycle reduced by 15 days of project which has integrated system. Besides this, the execution cycle of project which only contains equipment and cubicles reduced by 8 days or more.

\section{G. Control Phase}

In control phase, we work out some measures to strengthen the improving effect. First, the corresponding system document is modified and fixed, and relative workers are trained based on the fixed document. Second, we analyze data through the whole project and detect the relative accuracy of project scheduling based on HERE, thus we can get the real-time information on project's completing. At present, the improving plans have been fixed, promoted and applied, which leads to high efficiency.

\section{CONCLUSION}

This paper researched on the situation that delaying of order's delivery and serious inventory in Nanjing SAC 
Automation Co., Ltd. based on data from March in 2014 to March in 2015. Theory of Six Sigma is used to find the key factors which influenced the project scheduling, then corresponding improving rules are carried out and fixed through the platform HERE, which improved the formulating level of project scheduling, revealed in two indexes, OTD and inventory level.

The application of Six Sigma optimized the planning process of project scheduling, and improved the working efficiency and customers satisfaction degree, which is worth promoting in more areas. The shortage of this paper is that indexes reflected order's delivery and invention are too

[3] Quan Li. The progress of planning management research [J]. Business, 2016 (9): 7-8.

[4] Chakrabarty A, Tan K C. The current state of six sigma application in services [J]. Journal of Service Theory \& Practice, 2012, 17(2):194208.

[5] Mcadam R, Hazlett S. An absorptive capacity interpretation of Six Sigma [J]. Journal of Manufacturing Technology Management, 2010, volume 21(5):624-645.

[6] Antony J. Some pros and cons of six sigma: an academic perspective [J]. TQM Magazine, 2013, 16(4):303-306.

[7] Wang Yugan, Fan Shuhai, Pan Mi Mi, et al. Application of Six Sigma Management Based on Minitab in Energy Saving Lamp Assembly [J]. Industrial Engineering and Management, 2011, 16 (3): 131-137. partial, and it is necessary to explore more comprehensive indexes to define them, making the research more rigorous.

\section{REFERENCES}

[1] Baykasoğlu A, Özbakır L. A grammatical optimization approach for integrated process planning and scheduling $[\mathrm{J}]$. Journal of Intelligent Manufacturing, 2009, 20(2):211-221.

[2] Chen S P. Analysis of critical paths in a project network with fuzzy activity times [J]. European Journal of Operational Research, 2007, 183(1):442-459. 